\title{
Assessing effective interventions to improve trial retention: do they contain behaviour change techniques?
}

Eilidh M. Duncan ${ }^{*}(\mathbb{D}$, Tina Bennett and Katie Gillies

\begin{abstract}
Background: Clinical trials often struggle to retain the number of participants required to make valid and reliable assessments about the effectiveness of treatments. Several individual randomised comparisons of interventions to improve retention in trials have been shown to be effective. Many of these retention interventions target participants' behaviour (e.g. returning questionnaires or attending a follow-up visit). Although not designed as such, these interventions can be thought of as behaviour change interventions. By coding the constituent behaviour change components of effective retention interventions, the interventions' potential 'active ingredients' responsible for improvements in retention can be identified and maximised for future gains.

Methods: Studies reporting effective retention interventions were identified from existing meta-analyses in the literature. Published manuscripts and intervention and comparator group material were coded into their behaviour change techniques (BCTs) using the BCT taxonomy version 1. Two authors independently coded materials using a standardised coding manual and discussed any disagreements to reach consensus. Data on study characteristics including host trial context, timing, mode of delivery and dosage of retention intervention were recorded.

Results: Two intervention types were identified as having evidence of improving retention in existing metaanalyses: monetary incentives and electronic prompts. None of the interventions identified from the included studies explicitly stated a theoretical rationale for their development. BCTs were identified in both intervention and comparator groups across both intervention types and there was heterogeneity with regard to their presentation within and across interventions. The BCTs identified in the 'monetary incentive' interventions differed to the comparator group. Contrastingly, the BCTs identified in 'electronic prompts' interventions were identical in both the control and intervention groups (within studies) and differed only in terms of mode of delivery and dosing.
\end{abstract}

Conclusions: Attending a measurement visit or returning a questionnaire is a behaviour and trialists should be mindful of this when designing retention interventions. Our work in this area provides some of the first evidence of the impact of implicit use of BCTs in retention interventions and highlights their potential promise for future trials.

Keywords: Participant retention, Clinical trials, Interventions, Behaviour change techniques, Theory

\footnotetext{
* Correspondence: e.duncan@abdn.ac.uk

Health Services Research Unit, Institute of Applied Health Sciences, University
} of Aberdeen, Aberdeen, UK

(c) The Author(s). 2020 Open Access This article is distributed under the terms of the Creative Commons Attribution 4.0 International License (http://creativecommons.org/licenses/by/4.0/), which permits unrestricted use, distribution, and reproduction in any medium, provided you give appropriate credit to the original author(s) and the source, provide a link to the Creative Commons license, and indicate if changes were made. The Creative Commons Public Domain Dedication waiver (http://creativecommons.org/publicdomain/zero/1.0/) applies to the data made available in this article, unless otherwise stated. 


\section{Background}

Clinical trials often struggle to retain the number of participants required on which to make valid and reliable assessments about effectiveness of treatments. It is common for many trial participants (sometimes more than $20 \%)$ to drop out before the trial finishes [1]. Moreover, $50 \%$ of trials have loss to follow-up of over $11 \%$ [1]. The threat of poor retention is a problem for trials and this is further recognised amongst the trials community by its position in joint second as a research priority area for trials methodology [2].

Many strategies are used in an informal way to maximise the numbers of participants staying in a trial to the end, in other words providing outcome data. Yet few strategies to improve retention have robust evidence of effectiveness. Several individual randomised comparisons of interventions to improve retention in trials suggest promise of being effective. However, a Cochrane review of interventions to improve retention to randomised controlled trials revealed that, when pooled in metaanalyses, only a handful of these have a cumulative effect across studies [3]. The 38 trials included within the meta-analysis were grouped into six broad categories of interventions; incentives (monetary and non-monetary), communication strategies (e.g. enhanced cover letter, additional reminders, recorded delivery), questionnaire format (e.g. varying the length or ordering of questions or relevance), participant case management (i.e. increasing support to participants to facilitate retention), behavioural (increasing participants' motivation) and methodological interventions (i.e. varying aspects of study design such as unblinding treatment allocation) [3]. Only monetary incentives (conditional and unconditional) showed a positive pooled effect on retention in terms of postal and electronic questionnaire response [3]. The effect of other intervention categories was unclear and the review authors concluded more research was required to ascertain effectiveness. Another metaanalysis of interventions to improve retention in RCTs has also been conducted outside of the Cochrane review which highlights the effectiveness of electronic prompts to improve return of postal questionnaires [4].

It is currently unclear whether existing interventions to improve participant retention are based on best evidence, i.e. it is unknown what guided intervention choice, how the intervention was developed and whether a logic model was used to guide interpretation of effect. Moreover, retention within clinical trials involves behaviours; it involves participants completing and returning questionnaires and/or attending site visits, or not. Whilst there is a wealth of theories and evidence about how best to change health behaviour in patients (e.g. promoting health lifestyles), the extent to which interventions targeting retention make use of this evidence is unknown. Identifying and specifying the behaviourally active components of interventions will allow for better understanding of what works (and why) and allow for better replication of successful interventions across different trials testing different clinical interventions in a range of clinical settings.

The aim of this study was to establish whether interventions shown to improve retention to randomised trials are theoretically framed and to identify whether any behaviour change techniques are used (implicitly or explicitly) within these effective interventions.

\section{Methods}

Published reports of interventions shown to be effective (on meta-analysis) at improving retention were reviewed for any reported theoretical underpinning in their development. Intervention descriptions were coded using the Behaviour Change Technique Taxonomy (BCTTv1), which is a hierarchically structured taxonomy of 93 distinct behaviour change techniques (BCTs; the smallest active ingredients of interventions to change behaviour [5]).

\section{Inclusion criteria}

1. Clinical trials that included a nested randomised trial of an intervention to improve retention (i.e return of outcome data)

2. Trials of interventions targeting retention that show evidence of benefit on meta-analysis

\section{Exclusion criteria}

1. Trials of interventions targeting 'retention' that did not focus on data collection, e.g. intervention adherence

2. Trials of interventions that were not within a clinical trial setting

3. Trials that solely measured retention as 'time taken to respond' rather than 'response rate'

4. Trials that tested aspects of trial design (e.g. open design) on retention, i.e. had no behavioural component

5. Retention intervention trials that were shown to be individually significant but not evidence at metaanalysis, i.e. individual evaluations

\section{Search methods for identification of studies}

The existing Cochrane review was the main source for interventions examined in this literature review [3]. Of the 38 included trials, we retained those whose trials showed statistically significant findings on meta-analysis. An additional study, known to the authors, which included a meta-analysis of interventions to improve 
retention in clinical trials (which were not included in the Cochrane review), was also included [4]. A grey literature search (conducted through a citation analysis of the Cochrane review on interventions to improve retention) was also conducted to ensure no additional reviews of retention interventions were eligible for inclusion.

\section{Selection of studies}

Comparisons from the Cochrane review were examined for statistical significance [3]. If the pooled effect of an intervention on sub-group analysis (e.g. monetary incentives) was significant, all trials within that comparison were selected and retention interventions included for further analysis. The Cochrane review identified monetary incentives to be the only effective intervention to improve retention when individual studies were combined in a meta-analysis. Similarly, Clark et al. included a meta-analysis that identified electronic prompts to be effective and these were included in our analysis [4]. The individual studies from each of these meta-analyses were selected for further analysis of interventions.

\section{Data collection and analysis}

Demographic data were extracted from the included studies about the host trial descriptors (clinical population, intervention, time of follow up) and the category of retention intervention (i.e. monetary or communication). Information about group comparisons, target behaviour (i.e. postal questionnaire response rate, clinic visit), condition of incentive of the monetary interventions, sample size and effect size was also recorded.

Corresponding authors of the studies were emailed to request further information about the embedded trial and the retention interventions being tested. Exact content and wording of the intervention (e.g. copies of text messages, emails, cover letters to introduce the intervention and follow-up letters) and the comparator used in the retention trials were requested for coding using the BCTTv1. If the published articles mentioned any theory to inform the development or choice of intervention, this was recorded in the data extraction forms verbatim. The published BCTTv1 (containing 93 individual BCTs [5]) was used to code verbatim descriptions of interventions. A coding manual which included BCT definitions and examples from the published taxonomy and was edited with additional coding rules (developed and agreed by coders ED and TB) was created and used for reference during coding (available from authors by request). Additional coding rules were generated through discussions within the study team (ED, TB and KG) and applied during coding to ensure consistency between and within coders. All data were double coded by ED (a trained and experienced $\mathrm{BCT}$ coder) and $\mathrm{TB}$ (a trained BCT coder).
BCTs were recorded for both intervention and comparator groups. Both authors compared answers to highlight and resolve discrepancies. Discrepancies that remained despite further discussion were brought to the rest of the research team for group discussion. For each identified $\mathrm{BCT}$, the mode of delivery (e.g. postal, telephone, email) and the dose (i.e. value of intervention and/or how many times it was delivered) was also recorded.

\section{Results}

\section{Description of studies}

A total of seven published retention trials were deemed eligible for inclusion and selected for analysis (see Table 1 for summary of study characteristics). The included studies were conducted in two countries-UK and USA - and published from 2003 to 2015. Retention time points in the host trials also varied, ranging from 2 weeks to 12 months. Each study included between 125 and 2591 participants. The trials in which the embedded studies were set included a range of clinical contexts, such as migraine, chronic obstructive pulmonary disease, back pain, smoking cessation, neck injury, preterm labour and problem drinking. Four trials used or offered a monetary incentive to improve retention [6-9] and three trials focused on electronic prompts to improve trial retention $[4,10,11]$. One included study included two trials of monetary interventions to improve retention; therefore, eight interventions in total were coded from these seven reports [9].

Clark et al. [4], Ashby et al. [10] and Man et al. [11] looked at the effects of electronic reminders on improving retention rates in returning follow-up postal questionnaires. These studies investigated the effects of electronic prompting (defined by the authors as the intervention coinciding with receipt of the questionnaire) sent via email and/or text message reminders. Control groups did not receive the electronic prompt.

Bauer et al. [6], Gates et al. [7], Kenyon et al. [8] and Khadjesari et al. [9] looked at the effects of what was termed a monetary incentive/reward on improving retention rates to questionnaire return (and return of sample collection kits [6]). Gates et al.[7] and Kenyon et al. [8] randomised participants to receive either a $£ 5$ gift voucher or no gift voucher with their postal questionnaire. Bauer et al. randomised participants to either US $\$ 10$ or US\$2, compared to no incentive to improve return of sample collection kits [6]. All three of these trials provided the monetary incentive before the completed questionnaire was received, i.e. receipt of the incentive was not conditional on the behaviour being performed [6-8]. As an online study, Khadjesari et al. included two separate trials within their study[9]. In trial 1 non-responders were randomised to three different 
Table 1 Characteristics of included studies

\begin{tabular}{|c|c|c|c|c|c|c|c|c|c|c|}
\hline Study ID & Year & Country & $\begin{array}{l}\text { Clinical } \\
\text { population }\end{array}$ & $\begin{array}{l}\text { Timing of } \\
\text { follow up }\end{array}$ & $\begin{array}{l}\text { Retention } \\
\text { intervention }\end{array}$ & $\begin{array}{l}\text { Timing of } \\
\text { retention } \\
\text { intervention }\end{array}$ & $\begin{array}{l}\text { Target } \\
\text { behaviour }\end{array}$ & $\begin{array}{l}\text { Sample } \\
\text { size }\end{array}$ & $\begin{array}{l}\text { Effect } \\
\text { size }\end{array}$ & $\begin{array}{l}\text { Explicit use } \\
\text { of theory in } \\
\text { development? }\end{array}$ \\
\hline \multicolumn{11}{|c|}{ Electronic prompts } \\
\hline Ashby [10] & 2011 & UK & $\begin{array}{l}\text { Food sensitivity } \\
\text { for prevention of } \\
\text { migraine }\end{array}$ & $\begin{array}{l}4 \text { week follow } \\
\text { up }\end{array}$ & $\begin{array}{l}\text { Electronic } \\
\text { prompt: } \\
\text { SMS/email/ } \\
\text { both }\end{array}$ & $\begin{array}{l}\text { Coincide with } \\
\text { receipt of } \\
\text { questionnaire }\end{array}$ & $\begin{array}{l}\text { Return of postal } \\
\text { questionnaire }\end{array}$ & 148 & $\begin{array}{l}5.4 \% \\
(95 \% \\
C l 4.6 \\
15.4)\end{array}$ & No \\
\hline Clark [4] & 2015 & UK & $\begin{array}{l}\text { Identifying } \\
\text { individuals with } \\
\text { chronic } \\
\text { obstructive } \\
\text { pulmonary } \\
\text { disease }\end{array}$ & $\begin{array}{l}\text { Between } 2 \\
\text { and } 6 \text { months } \\
\text { (dependent } \\
\text { on site) }\end{array}$ & $\begin{array}{l}\text { Electronic } \\
\text { prompt: } \\
\text { SMS/email/ } \\
\text { both }\end{array}$ & $\begin{array}{l}\text { Coincide with } \\
\text { receipt of } \\
\text { questionnaire- } \\
\text { '2 days after the } \\
\text { questionnaire } \\
\text { was sent' }\end{array}$ & $\begin{array}{l}\text { Return of postal } \\
\text { questionnaire }\end{array}$ & 437 & $\begin{array}{l}8.8 \% \\
(95 \% \\
\mathrm{Cl} \\
0.11 \\
17.7)\end{array}$ & No \\
\hline Man [11] & 2011 & UK & $\begin{array}{l}\text { Yoga for } \\
\text { treatment of } \\
\text { lower back pain }\end{array}$ & 6 months & $\begin{array}{l}\text { Electronic } \\
\text { prompt: } \\
\text { SMS/email }\end{array}$ & $\begin{array}{l}\text { Coincide with } \\
\text { receipt of } \\
\text { questionnaire- } \\
\text { 'on the day } \\
\text { that } \\
\text { participants } \\
\text { were due to } \\
\text { receive their } \\
\text { questionnaire' }\end{array}$ & $\begin{array}{l}\text { Return of postal } \\
\text { questionnaire }\end{array}$ & 125 & $\begin{array}{l}3 \% \\
(95 \% \\
\mathrm{Cl} 10 \\
16)\end{array}$ & No \\
\hline \multicolumn{11}{|c|}{ Monetary incentives } \\
\hline Bauer [6] & 2003 & USA & $\begin{array}{l}\text { Community } \\
\text { intervention trial } \\
\text { for smoking } \\
\text { cessation }\end{array}$ & 2 weeks & $\begin{array}{l}\text { Monetary } \\
\text { incentive } \\
\text { (cheque for } \\
\$ 10 \text { USD or } \\
\$ 2 \text { USD) }\end{array}$ & $\begin{array}{l}\text { At time of data } \\
\text { collection, i.e. } \\
\text { unconditional }\end{array}$ & $\begin{array}{l}\text { Sample } \\
\text { collection kits } \\
\text { and return of } \\
\text { postal } \\
\text { questionnaire }\end{array}$ & 300 & $\begin{array}{l}\mathrm{OR}= \\
1.66 \\
(95 \% \\
\mathrm{Cl} \\
0.83 \\
3.33)\end{array}$ & No \\
\hline Gates [7] & 2009 & UK & $\begin{array}{l}\text { Managing acute } \\
\text { whiplash injuries } \\
\text { in emergency } \\
\text { departments }\end{array}$ & $\begin{array}{l}4 \text { months and } \\
8 \text { months }\end{array}$ & $\begin{array}{l}\text { Monetary } \\
\text { incentive } \\
\text { ( } £ 5 \text { GBP } \\
\text { voucher) }\end{array}$ & $\begin{array}{l}\text { At time of data } \\
\text { collection-4 } 4 \\
\text { months or } 8 \\
\text { months, i.e. } \\
\text { unconditional }\end{array}$ & $\begin{array}{l}\text { Return of postal } \\
\text { questionnaire }\end{array}$ & 2144 & $\begin{array}{l}\text { RR } \\
1.10 \\
(95 \% \\
C l \\
1.05 \\
1.16)\end{array}$ & No \\
\hline Kenyon [8] & 2005 & UK & $\begin{array}{l}\text { Use of antibiotics } \\
\text { to improve } \\
\text { neonatal } \\
\text { outcomes in } \\
\text { preterm labour or } \\
\text { preterm rupture } \\
\text { of membranes- } \\
\text { long term follow } \\
\text { up }\end{array}$ & $\begin{array}{l}7 \text { years post } \\
\text { trial contact is } \\
\text { initiated by } \\
\text { letter. } \\
\text { Questionnaire } \\
\text { sent at } 2 \\
\text { weeks }\end{array}$ & $\begin{array}{l}\text { Monetary } \\
\text { reward (£5 } \\
\text { GBP } \\
\text { voucher) }\end{array}$ & $\begin{array}{l}6 \text { weeks post } \\
\text { first } \\
\text { questionnaire } \\
\text { with reminder, } \\
\text { i.e. } \\
\text { unconditional }\end{array}$ & $\begin{array}{l}\text { Return of postal } \\
\text { questionnaire }\end{array}$ & 722 & $\begin{array}{l}11.7 \% \\
(95 \% \\
C \mid 4.7 \\
18.6)\end{array}$ & No \\
\hline $\begin{array}{l}\text { Khadjesari } \\
{[9]}\end{array}$ & 2011 & UK & $\begin{array}{l}\text { Reducing alcohol } \\
\text { levels amongst } \\
\text { problem drinkers }\end{array}$ & $\begin{array}{l}\text { Study 1: } 3 \\
\text { months } \\
\text { Study 2: } 12 \\
\text { months }\end{array}$ & $\begin{array}{l}\text { Study 1: } \\
\text { Monetary } \\
\text { incentive } \\
\text { 1. } £ 5 \\
\text { Amazon } \\
\text { voucher } \\
\text { 2. } £ 5 \\
\text { charitable } \\
\text { donation } \\
\text { 3. } 250 \\
\text { prize draw } \\
\text { Study 2: } \\
\text { Monetary } \\
\text { incentive } \\
\text { (£10 } \\
\text { Amazon } \\
\text { voucher) }\end{array}$ & $\begin{array}{l}\text { Study 1: } \\
\text { promise of } \\
\text { incentive within } \\
1 \text { week of } \\
\text { questionnaire, } \\
\text { i.e. conditional } \\
\text { Study 2: } \\
\text { promise of } \\
\text { incentive at } \\
\text { each email } \\
\text { reminder, i.e. } \\
\text { conditional }\end{array}$ & $\begin{array}{l}\text { Return of } \\
\text { online } \\
\text { questionnaire- } \\
\text { linked in email }\end{array}$ & $\begin{array}{l}\text { Study 1: } \\
1226 \\
\text { Study 2: } \\
2591\end{array}$ & $\begin{array}{l}\text { Study } \\
1: 2 \% \\
(95 \% \\
\mathrm{Cl}-3 \text {, } \\
7) \\
\text { Study } \\
2: 9 \% \\
(95 \% \\
\mathrm{Cl} 5 . \\
12)\end{array}$ & No \\
\hline
\end{tabular}


interventions-an offer of a $£ 5$ Amazon voucher, offer of a $£ 5$ donation to Cancer Research UK or offer of a $£ 250$ prize draw-or no offer of incentive. After a threemonth follow-up, remaining non-responders were further randomised in trial 2 to receive either an offer of a $£ 10$ Amazon voucher or no offer of incentive. The offer of the incentive in these evaluations was contingent on the behaviour being performed and was only received when the questionnaire was returned.

None of the embedded trials explicitly mentioned an underlying theory in their development of the interventions to improve retention.

\section{Behaviour change techniques coding}

A summary of BCT coding across all trials is shown in Table 2 and examples of BCT coded content for interventions in Additional file 2. The BCT 'Social support practical' ("advise on, arrange or provide practical help for performance of the behaviour") was coded across three trials, for example where a telephone number was provided to participants with the offer of help to complete questionnaires in event of difficulties. 'Instruction on how to perform a behaviour' ("advise or agree on how to perform the behaviour") was coded within five trials, for example when participants were informed how to submit their questionnaire responses online. 'Information about health consequences' ("provide information (e.g. written, verbal, visual) about health consequences of performing the behaviour") and the related $\mathrm{BCT}$
'Information about social and environmental consequences ("provide information about social and environmental consequences of the behaviour") was coded across four trials when retention was linked to the overall health/social or environmental question the host trial was trying to answer. 'Credible source' ("present verbal or visual communication from a credible source in favour of or against the behaviour") was used within two trials and was coded when letters/reminder letters/emails included an institutional letterhead or were signed by the study coordinator. 'Adding objects to the environment' ("add objects to the environment in order to facilitate performance of the behaviour") was coded for five trials, for example when pre-paid envelopes were provided with the questionnaire to facilitate return. The number of BCTs identified within intervention (or comparators) varied across studies, ranging from a minimum of one to a maximum of seven (median of 5).

The most commonly coded BCT within both the 'electronic prompts' trials and the 'monetary incentive' trials was 'Prompts/Cues' defined as "introduce or define environmental or social stimulus with the purpose of prompting or cueing the behaviour. The prompt or cue would normally occur at the time or place of performance." An example of this strategy is a letter reminding participants about completing a questionnaire. This letter may be received as part of the control comparator and as part of the intervention (i.e. accompanies the monetary incentive) and the content of which could vary accordingly to

Table 2 Summarised behaviour change technique coding for the interventions tested in the included studies

\begin{tabular}{|c|c|c|c|c|c|c|c|c|c|c|c|}
\hline \multirow[t]{3}{*}{$\mathrm{BCT}$ grouping } & \multirow{3}{*}{$\begin{array}{l}\mathrm{BCT} \\
\text { reference }\end{array}$} & \multirow{3}{*}{ BCT name } & \multicolumn{8}{|l|}{ Trials } & \multirow{3}{*}{$\begin{array}{l}\text { Frequency } \\
\text { of BCTs } \\
\text { across } \\
\text { intervention }\end{array}$} \\
\hline & & & \multicolumn{3}{|c|}{ Electronic prompts } & \multicolumn{5}{|c|}{ Monetary incentives } & \\
\hline & & & $\begin{array}{l}\text { Ashby } \\
{[10]}\end{array}$ & $\begin{array}{l}\text { Clark } \\
{[4]}\end{array}$ & $\begin{array}{l}\text { Man } \\
{[11]}\end{array}$ & $\begin{array}{l}\text { Bauer } \\
{[6]}\end{array}$ & $\begin{array}{l}\text { Gates } \\
{[7]}\end{array}$ & $\begin{array}{l}\text { Kenyon } \\
{[8]}\end{array}$ & $\begin{array}{l}\text { Khad. } \\
1[9]\end{array}$ & $\begin{array}{l}\text { Khad. } \\
2[9]\end{array}$ & \\
\hline Social support & 3.2 & Social support (practical) & & ++ & & ++ & ++ & & & & 3 \\
\hline $\begin{array}{l}\text { Shaping } \\
\text { knowledge }\end{array}$ & 4.1 & $\begin{array}{l}\text { Instruction on how to perform the } \\
\text { behaviour }\end{array}$ & & ++ & ++ & ++ & ++ & & ++ & ++ & 6 \\
\hline \multirow[t]{2}{*}{$\begin{array}{l}\text { Natural } \\
\text { consequences }\end{array}$} & 5.1 & $\begin{array}{l}\text { Information about health } \\
\text { consequences }\end{array}$ & & ++ & & & & & & & 1 \\
\hline & 5.3 & $\begin{array}{l}\text { Information about social and } \\
\text { environmental consequences }\end{array}$ & & & & & ++ & & ++ & ++ & 3 \\
\hline Associations & 7.1 & Prompts/cues & ++ & ++ & ++ & ++ & ++ & ++ & ++ & ++ & 8 \\
\hline $\begin{array}{l}\text { Comparison of } \\
\text { outcomes }\end{array}$ & 9.1 & Credible source & & ++ & & & ++ & & & & 2 \\
\hline \multirow{4}{*}{$\begin{array}{l}\text { Reward and } \\
\text { threat }\end{array}$} & 10.1 & Material incentive (behaviour) & & & ++ & & & & & & 1 \\
\hline & 10.2 & Material reward (behaviour) & & & & + & + & + & & & 3 \\
\hline & 10.8 & Incentive (outcome) & & & & & & & + & + & 2 \\
\hline & 10.10 & Reward (outcome) & & & & & & & + & + & 2 \\
\hline Antecedents & 12.5 & Adding objects to the environment & & ++ & ++ & ++ & ++ & ++ & & & 5 \\
\hline \multicolumn{3}{|c|}{ Total number of BCTs identified per study } & 1 & 6 & 4 & 5 & 7 & 3 & 5 & 5 & \\
\hline
\end{tabular}

$++\mathrm{BCT}$ present in intervention and control

$+\mathrm{BCT}$ present in intervention only 
also become part of the intervention. This prompting $\mathrm{BCT}$ was present across all trials; however, this was present within both control and intervention groups, making it difficult to draw conclusions about any influence on overall effects. The mode of delivery of this BCT employed across trials varied and included email [9], letter [8], phone [6, 7] and multiple modes, including SMS text message $[4,10,11]$, as shown in Table 3.

The monetary incentive strategies used within five interventions are shown in Table 4. When these are coded into BCTs it becomes clear that two of the interventions employed the BCTs 'Incentive (outcome)' ('Inform that a reward will be delivered if and only if there has been effort and/or progress in achieving the behavioural outcome") and 'Reward (outcome)' ("arrange for the delivery of a reward if and only if there has been effort and/or progress in achieving the behavioural outcome") [9]. For these two interventions, the behavioural outcome is completion of an online questionnaire. For the remaining three trials the intervention's active ingredient could not be coded directly onto the existing BCT taxonomy [6-8]. As such, it was coded to the closest current match within the taxonomy, which was 'Material reward (behaviour)' ("arrange for the delivery of money, vouchers or other valued objects if and only if there has been effort and/or progress in performing the behaviour"). However, the monetary rewards in these trials were unconditional upon behaviour. Participants were provided with the incentive regardless of whether they then returned the questionnaire. No BCTs within the current taxonomy clearly capture this kind of unconditional reward.

\section{Discussion}

To our knowledge, we are one of the first research teams to consider retention as a behaviour and to apply a

Table 3 Mode of delivery and dose of the behaviour change technique prompts/cues across all trials

\begin{tabular}{|c|c|c|c|}
\hline \multirow[t]{2}{*}{ Trials } & & \multicolumn{2}{|l|}{ BCT - 7.1 Prompts/cues } \\
\hline & & Mode of delivery & Dose \\
\hline \multicolumn{4}{|l|}{ Electronic prompts } \\
\hline \multirow[t]{5}{*}{ Ashby [10] } & Intervention group & 1) $\mathrm{SMS}$ & All once (but unclear) \\
\hline & & 2) Email & \\
\hline & & 3) SMS and email & \\
\hline & & 4) Telephone reminder & \\
\hline & Control group & 1) Telephone reminder & Once \\
\hline \multirow[t]{5}{*}{ Clark [4] } & Intervention group & 1) $\mathrm{SMS}$ & 1) Unclear \\
\hline & & 2) Email & 2) Unclear \\
\hline & & 3) SMS and email & 3) Unclear \\
\hline & & 4) Written letter & 4) Twice \\
\hline & Control group & 1) Written letter & 1) Twice \\
\hline \multirow[t]{5}{*}{ Man [11] } & Intervention group & 1) $S M S$ & 1) Unclear \\
\hline & & 2) Email & 2) Unclear \\
\hline & & 3) SMS and email & 3) Unclear \\
\hline & & 4) Reminder letters: post & 4) Unclear \\
\hline & Control group & 4) Reminder letters: post & 1) Unclear \\
\hline \multicolumn{4}{|l|}{ Monetary incentives } \\
\hline \multirow[t]{2}{*}{ Bauer [6] } & Intervention group & 1) Follow-up calls & 1) Unclear \\
\hline & Control group & 1) Follow-up calls & 1) Unclear \\
\hline \multirow[t]{2}{*}{ Gates [7] } & Intervention group & 1) Telephone reminder & 1) $U$ to three \\
\hline & Control group & 1) Telephone reminder & 1) Up to three \\
\hline \multirow[t]{2}{*}{ Kenyon [8] } & Intervention group & 1) Reminder letter & 1) Once \\
\hline & Control group & 1) Reminder letter & 1) Once \\
\hline \multirow[t]{2}{*}{ Khadjesari 1 [9] } & Intervention group & 1) Email & 1) Up to three \\
\hline & Control group & 1) Email & 1) Up to three \\
\hline \multirow[t]{2}{*}{ Khadjesari 2 [9] } & Intervention group & 1) Email & 1) Up to three \\
\hline & Control group & 1) Email & 1) Up to three \\
\hline
\end{tabular}


Table 4 Behaviour change techniques, mode of delivery and dose for monetary reward interventions

\begin{tabular}{|c|c|c|c|c|c|c|c|}
\hline \multirow[t]{2}{*}{ Trials } & & \multicolumn{2}{|c|}{$\begin{array}{l}\text { BCT - 10.2, Material reward } \\
\text { (behaviour) }\end{array}$} & \multicolumn{2}{|c|}{$\begin{array}{l}\text { BCT - 10.8, Incentive } \\
\text { (outcome) }\end{array}$} & \multicolumn{2}{|c|}{ BCT - 10.10, Reward (outcome) } \\
\hline & & $\begin{array}{l}\text { Mode of } \\
\text { delivery }\end{array}$ & Dose & $\begin{array}{l}\text { Mode of } \\
\text { delivery }\end{array}$ & Dose & $\begin{array}{l}\text { Mode of } \\
\text { delivery }\end{array}$ & Dose \\
\hline \multirow[t]{2}{*}{ Bauer [6] } & Intervention & $\begin{array}{l}\text { 1) Postal } \\
\text { cheque }\end{array}$ & $\begin{array}{l}\text { 1) Once } \\
\text { USD10 cheque } \\
\text { or } \\
\text { USD2 cheque }\end{array}$ & $x$ & $\mathrm{n} / \mathrm{a}$ & $x$ & $\mathrm{n} / \mathrm{a}$ \\
\hline & Control & $x$ & $\mathrm{n} / \mathrm{a}$ & $x$ & $\mathrm{n} / \mathrm{a}$ & $x$ & $\mathrm{n} / \mathrm{a}$ \\
\hline \multirow[t]{2}{*}{ Gates [7] } & Intervention & 1) postal & $\begin{array}{l}\text { 1) Once } \\
\text { GBP5 voucher }\end{array}$ & $x$ & $\mathrm{n} / \mathrm{a}$ & $x$ & $\mathrm{n} / \mathrm{a}$ \\
\hline & Control & $x$ & $\mathrm{n} / \mathrm{a}$ & $x$ & $\mathrm{n} / \mathrm{a}$ & $x$ & $\mathrm{n} / \mathrm{a}$ \\
\hline \multirow[t]{2}{*}{ Kenyon [8] } & Intervention & $\begin{array}{l}\text { 1) Postal } \\
\text { voucher }\end{array}$ & $\begin{array}{l}\text { 1) Once } \\
\text { GBP5 voucher }\end{array}$ & $x$ & $\mathrm{n} / \mathrm{a}$ & $x$ & $\mathrm{n} / \mathrm{a}$ \\
\hline & Control & $x$ & $\mathrm{n} / \mathrm{a}$ & $x$ & $\mathrm{n} / \mathrm{a}$ & $x$ & $\mathrm{n} / \mathrm{a}$ \\
\hline \multirow[t]{2}{*}{$\begin{array}{l}\text { Khadjesari } 1 \\
{[9]}\end{array}$} & Intervention & $x$ & $\mathrm{n} / \mathrm{a}$ & 1) Via email & $\begin{array}{l}\text { 1) } \\
\text { Once }\end{array}$ & 1) Via email & $\begin{array}{l}\text { 1) Once } \\
\text {-Offer GBP5 Amazon voucher } \\
\text { or } \\
\text { - Offer of GBP5 CRUK donation } \\
\text { or } \\
\text { - Offer of entry into GBP } 250 \text { charitable prize } \\
\text { draw }\end{array}$ \\
\hline & Control & $x$ & $\mathrm{n} / \mathrm{a}$ & $x$ & $\mathrm{n} / \mathrm{a}$ & $x$ & \\
\hline \multirow[t]{2}{*}{$\begin{array}{l}\text { Khadjesari } 2 \\
\text { [9] }\end{array}$} & Intervention & $x$ & $\mathrm{n} / \mathrm{a}$ & 1) Via email & $\begin{array}{l}\text { 1) } \\
\text { once }\end{array}$ & 1) Via email & $\begin{array}{l}\text { 1) Once } \\
\text { GBP10 Amazon voucher }\end{array}$ \\
\hline & Control & $x$ & n/a & $x$ & n/a & $x$ & n/a \\
\hline
\end{tabular}

$x$ not present, $n / a$ not applicable

standardised taxonomy to specify the active ingredients of interventions. The interventions included in this study that aimed to improve retention did not explicitly state a theoretical rationale underpinning their development or application. Without this, researchers are limited to pragmatic over theoretically informed solutions. With an explicit theoretical rationale, interventions to improve retention could be more effective and better replicated in other contexts if the mechanism of action was better understood. It should be unsurprising that all retention interventions included in our analysis were identified as including the prompts/cues BCT. For some of the included interventions, this prompting was an explicit planned action of the intervention (e.g. electronic prompts), whereas for others it was an implicit aspect, for example the use of a letter to inform participants of a monetary incentive also doubles as a prompt. Applying a standardised taxonomy to specify the active ingredients of retention intervention strategies has revealed heterogeneity in the active ingredients included and in the modes and dose of delivery of these potentially active ingredients.

The three electronic prompt studies varied with regard to which BCTs were identified, even though the three studies originate from the same research team $[4,10,11]$. The coding we have carried out shows that a variety of active ingredients have been used within one group of 'communication strategies', electronic prompts, making it difficult to know which aspects of the intervention may be effective and which not. Furthermore, the trials that have tested these types of strategies have included active ingredients (or BCTs) within both the control and intervention groups, further complicating the picture. It is also interesting to note that of these three studies, the one with the biggest improvement in retention is also the intervention which we identified most BCTs in (for this intervention type). This suggests that other factors, such as varying the dose or mode of delivery of these active ingredients, may also play a role in how effective or not these types of strategies may be. Better specification and reporting of retention interventions would allow for accumulation of knowledge about what works in what circumstances. Using an established taxonomy to do so will enable the specification of 'standard care', ensuring that evaluated interventions are distinct from standard care control groups [12].

The active component of providing unconditional monetary interventions could not be accurately coded to the existing BCT taxonomy. We agreed as a team to code it to the closest existing BCT in the taxonomy, which was 'Material reward (behaviour)' defined as "arrange for the delivery of money, vouchers or other valued objects if and only if there has been effort and/or progress in performing the behaviour". However, in the 
unconditional monetary interventions identified in this review, no effort or progress in behaviour was required before the monetary reward was delivered. The other alternative BCTs to code were within the category 'Incentives'; however, these require participants to be informed in advance of the potential for future reward that is again conditional on effort/progress in behaviour. Clearly neither BCT classification is strictly accurate for the unconditional nature of these monetary interventions. An unconditional monetary intervention could be theorised to influence behaviour in several ways. Receiving money along with a request to return questionnaires may create an expectation of future rewards if participants continue to stay within the trial (and therefore work as an incentive). It may work through creating a social expectation of retention behaviour (e.g. I've been given this money to complete the questionnaire and now it is expected of me that I should) and working through injunctive norms (which influence behaviour based on what people think is 'right' to do based on morals or beliefs) [13]. Further research would be needed in order to compare the effectiveness of conditional and unconditional monetary interventions on retention of participants.

The results from our study suggest that BCTs are already explicitly embedded in retention interventions (and sometimes their comparators). There is now emerging evidence of a role for explicitly embedding BCTs to improve aspects of retention, such as return of postal questionnaires. Evidence from one trial evaluating a theoretically informed letter to target return of trial questionnaires showed a $6 \%$ improvement in response rates in the intervention group [14]. Indeed this work is being extended to consider how to actively develop theoretically informed retention interventions that are embedded and produced in participants' accounts of the barriers to data collection [15]. It is interesting to note that of the seven studies we included in our analysis, only one conducted preliminary work with patient partners to identify which interventions may be most appropriate in their setting [9].

This study has a number of strengths and limitations. We applied this approach to studies included within existing systematic reviews that showed effectiveness through meta-analysis. Future studies may wish to examine the active ingredients of interventions that have been shown not to have an impact on retention and thereby build the evidence about what does not work under what circumstances to better inform development of effective interventions. Behavioural analysis, through BCT coding, of interventions included in Cochrane reviews on both recruitment and retention to trials could make important contributions to our understanding of how interventions targeting potential participants (or trial staff) behaviour does or does not have an effect.

\section{Conclusions}

Given the importance on retaining participants for trial success, considering retention through a behavioural lens may be a fruitful area for trialists wishing to build an evidence base on how to intervene successfully to optimise retention. The BCT-taxonomy used in this study currently has 93 BCTs included, which highlights the variety of potential components that could be tested. In addition, identifying the barriers and facilitators to participant retention and mapping to BCTs hypothesised to change these may also have potential. These tools and approaches could help to inform the design of future retention interventions and enhance the validity of research within this area and the replicability of successful interventions.

\section{Supplementary information}

Supplementary information accompanies this paper at https://doi.org/10. 1186/s13063-020-4151-4.

Additional file 1. Word file providing the template data extraction form

Additional file 2. Word file providing example BCT content from retention interventions.

Additional file 3. Coding manual.

Acknowledgements

Not applicable.

\section{Authors' contributions}

KG conceived the idea for the project, participated in the design and contributed to the development of the protocol. TB participated in the design of the study, led the development of the protocol and contributed to further development. ED participated in the design of the study and contributed to further development of the protocol. All authors contributed to the editing of the manuscript and have read and approved the final manuscript.

Funding

This research was supported by the Chief Scientist Office of the Scottish Government's Health and Social Care Department. KG was supported by an MRC Methodology Research Fellowship (MR/L01193X/1).

\section{Availability of data and materials}

The datasets used and/or analysed during the current study are available from the corresponding author on reasonable request.

Ethics approval and consent to participate Not applicable.

Consent for publication

Not applicable.

Competing interests

The authors declare that they have no competing interests.

Received: 11 December 2019 Accepted: 6 February 2020

Published online: 21 February 2020

\section{References}

1. Walsh M, Sackett D, Deveraux PJ. When RCT participants are lost to follow up. Why even a few can matter. Clin Trials. 2015;12:537-9.

2. Tudur Smith C, Hickey H, Clarke M, Blazeby J, Williamson P. The trials methodological research agenda: results from a priority setting exercise. Trials. 2014;15:32. 
3. Brueton VC, Tierney J, Stenning S, Harding S, Meredith S, Nazareth I, Rait G. Strategies to improve retention in randomised trials. Cochrane Database Syst Rev. 2013;12:MR000032. https://doi.org/10.1002/14651858.MR000032. pub2.

4. Clark L, Ronaldson S, Dyson L, Hewitt C, Torgerson D, Adamson J. Electronic prompts significantly increase response rates to postal questionnaires: A randomized trial within a randomized trial and meta-analysis. J Clin Epidemiol. 2015;68(12):1446-50.

5. Michie S, Richardson M, Johnston M, Abraham C, Francis J, Hardeman W, et al. The behavior change technique taxonomy (v1) of 93 hierarchically clustered techniques: Building an international consensus for the reporting of behavior change interventions. Ann Behav Med. 2013;46(1):81-95.

6. Bauer JE, Rezaishiraz H, Head K, Cowell J, Bepler G, Aiken M, et al. Obtaining DNA from a geographically dispersed cohort of current and former smokers: Use of mail-based mouthwash collection and monetary incentives. Nicotine Tob Res. 2004;6(3):439-46.

7. Gates S, Williams MA, Withers E, Williamson E, Mt-lsa S, Lamb SE. Does a monetary incentive improve the response to a postal questionnaire in a randomised controlled trial? the MINT incentive study. Trials. 2009;10(1):44.

8. Kenyon S, Pike K, Jones D, Taylor D, Salt A, Marlow N, Brocklehurst P. The effect of a monetary incentive on return of a postal health and development questionnaire: A randomised trial [ISRCTN53994660]. BMC Health Serv Res. 2005;5(1):55.

9. Khadjesari Z, Murray E, Kalaitzaki E, White IR, McCambridge J, Thompson SG et al. Impact and costs of incentives to reduce attrition in online trials: Two randomized controlled trials. J Med Internet Res. 2011;13(1):e26. https://doi. org/10.2196/jmir.1523.

10. Ashby R, Turner G, Cross B, Mitchell N, Torgerson D. A randomized trial of electronic reminders showed a reduction in the time to respond to postal questionnaires. J Clin Epidemiol. 2011;64(2):208-12.

11. Man M, Tilbrook HE, Jayakody S, Hewitt CE, Cox H, Cross B, Torgerson DJ. Electronic reminders did not improve postal questionnaire response rates or response times: A randomized controlled trial. J Clin Epidemiol. 2011;64(9): $1001-4$.

12. Michie S, Abraham C, Eccles MP, Francis JJ, Hardeman W, Johnston M. Strengthening evaluation and implementation by specifying components of behaviour change interventions: A study protocol. Implement Sci. 2011;6(1): 10.

13. Berkowitz, A.D. The social norms approach: theory, research and annotated bibliography. 2004 [Online]. Available at http://www.alanberkowitz.com/ articles/social_norms.pdf.

14. Duncan A, Bonetti D, Clarkson J, Ramsay C. Improving trial questionnaire response rates using behaviour change theory. Trials. 2015;16 Suppl 2:92.

15. Gillies K, Bower P, Elliott J, MacLennan G, Newlands RSN, Ogden M, Treweek SP, Wells M, Witham M, Young B, Francis JJ. Systematic Techniques to Enhance rEtention in Randomised controlled trials: the STEER study protocol. Trials. 2018;19(1):197.

\section{Publisher's Note}

Springer Nature remains neutral with regard to jurisdictional claims in published maps and institutional affiliations.

Ready to submit your research? Choose BMC and benefit from:

- fast, convenient online submission

- thorough peer review by experienced researchers in your field

- rapid publication on acceptance

- support for research data, including large and complex data types

- gold Open Access which fosters wider collaboration and increased citations

- maximum visibility for your research: over $100 \mathrm{M}$ website views per year

At $\mathrm{BMC}$, research is always in progress.

Learn more biomedcentral.com/submissions 